IZA DP No. 9523

The Capability Threshold:

Re-examining the Definition of the Middle Class in an Unequal Developing Country

Ronelle Burger

Camren McAravey

Servaas van der Berg

November 2015 


\title{
The Capability Threshold: Re-examining the Definition of the Middle Class in an Unequal Developing Country
}

\author{
Ronelle Burger \\ University of Stellenbosch \\ Camren McAravey \\ University of Stellenbosch
}

Servaas van der Berg

University of Stellenbosch

and IZA

Discussion Paper No. 9523

November 2015

\author{
IZA \\ P.O. Box 7240 \\ 53072 Bonn \\ Germany \\ Phone: +49-228-3894-0 \\ Fax: +49-228-3894-180 \\ E-mail: iza@iza.org
}

\begin{abstract}
Any opinions expressed here are those of the author(s) and not those of IZA. Research published in this series may include views on policy, but the institute itself takes no institutional policy positions. The IZA research network is committed to the IZA Guiding Principles of Research Integrity.

The Institute for the Study of Labor (IZA) in Bonn is a local and virtual international research center and a place of communication between science, politics and business. IZA is an independent nonprofit organization supported by Deutsche Post Foundation. The center is associated with the University of Bonn and offers a stimulating research environment through its international network, workshops and conferences, data service, project support, research visits and doctoral program. IZA engages in (i) original and internationally competitive research in all fields of labor economics, (ii) development of policy concepts, and (iii) dissemination of research results and concepts to the interested public.
\end{abstract}

IZA Discussion Papers often represent preliminary work and are circulated to encourage discussion. Citation of such a paper should account for its provisional character. A revised version may be available directly from the author. 


\section{ABSTRACT \\ The Capability Threshold: Re-examining the Definition of the Middle Class in an Unequal Developing Country}

In a polarised and highly unequal country such as South Africa, it is unlikely that a definition of the middle class that is based on an income threshold will adequately capture the political and social meanings of being middle class. We therefore propose a multi-dimensional definition, rooted in the ideas of empowerment and capability, and find that the 'empowered middle class' has expanded significantly since 1993 also across vulnerable subgroups such as blacks, female-headed households and rural inhabitants. It also is much larger than when measured in terms of income. Differing trends between the middle class defined based on income and based on capabilities is attributed to improved capabilities have not been rewarded with a proportional increases in access to the labour market. It is disconcerting that links to the labour market improved only slightly and this is attributed to sluggish labour market growth and low quality of education. We find that the middle class tend to have lower expectations around social mobility than the vulnerable. It is concerning that vulnerable individuals harbour unrealistically high expectations of the social mobility of the households and do not understand the determinants of social mobility and labour market prospects possibly due to a mixture of heightened expectations following the political transition, but also the continued disconnection and marginalisation of vulnerable subpopulations from the mainstream economy.

JEL Classification: $\quad$ I32, I38, N97, D31

Keywords: middle class, capability approach, measurement, development, South Africa

Corresponding author:

Ronelle Burger

Department of Economics

University of Stellenbosch

Private Bag X1

Stellenbosch 7602

South Africa

E-mail: rburger@sun.ac.za 


\section{Introduction}

The notion of the middle class is powerful partly because it is linked to significant societal benefits. Schlemmer (2005) characterizes the middle class as one of the two vital components of any country wishing to succeed in today's dynamic and competitive global economy. In fact, he argues that "social organization and a self-confident middle class are the underpinnings of the socioeconomic and political pluralism that gives society the flexibility to adopt economic challenges" (2005: 113). A large and growing middle class is associated with a long list of economic, political and social benefits including social pacification, the support and development of market-based economic practices, growing demand and skills development (Hertova et al. 2010:6). According to Wheary (2009:75) it is "part consumer group and part social force, the new middle class is seen as a symbol of the steady retreat of poverty; an engine of the global economy; a creator of jobs; a new consumer market; a spur for nations to invest in public infrastructure, roads, and schools; and an advocate for social stability, or in some cases, wholesale change."

While the concept of the middle class is powerful, there have been considerable obstacles in applying it to developing countries. The middle class has typically been defined using income, occupation, self-identification or a vulnerability approach. Of these, income is the most widely used approach and the range of income measures employed includes percentiles, medians and double thresholds. While the use of such centrist measures clearly has a semantic basis, we argue that because societies in developing countries often lack a strong core a perfunctory analysis of a middle segment of the population (by eliminating the top and the bottom) is unlikely to yield a sensible basis for better understanding a country's social structure and prospects. Specifically, because much of the interest in the concept of the middle class is due to the societal and macroeconomic benefits associated with a large growing middle class it is problematic that there is little empirical basis for assuming that those who find themselves in the middle of the income distribution in developing countries will for instance represent an important segment of the consumer market or identify with one another or be moderate in their political views. Furthermore, we also argue that income is inadequate and narrow because it only represents only market-based channels for the realisation of aspirations - buying goods, services and experiences - excluding for instance, the effect of free public services and failing to capture the impact and value of political and social freedoms. Additionally, there are questions as to whether market prices adequately reflect the value that people attach to specific capacities.

Given that the notions of freedom and empowerment ${ }^{1}$ are at the heart of much of the literature on the benefits of the middle class (Hill, 2003; Alkire and Ibrahim, 2007; Narayan, 2002; Narayan and Petesch, 2007), this paper proposes the capability approach as an alternative multi-dimensional approach to defining the middle class. We opt for a multi-dimensional measure aimed at characterizing this group as having achieved a necessary minimum level in a number of dimensions representing key economic and social capabilities.

\footnotetext{
1 The term empowerment is commonly used to indicate both a process (of empowering groups or individuals) and an outcome (a person or group is empowered).
} 
This approach has strong conceptual foundations because the theory of development and selfactualisation underlying this work centres on choice and opportunity, which resonates well with the theories of the middle class that depict members of this group as empowered, capacitated and economically secure individuals who are free to pursue their personal goals and aspirations. This approach to defining the middle class has more robust linkages to the benefits ascribed to this group, such as its role as a stabilising force and an engine for economic growth.

We suggest South Africa as a laboratory for implementing this rival approach to defining the middle class because the country has long lacked a substantial social core and is also plagued by extreme inequality, social polarization and political fragmentation. Inequality and poverty are pervasive, with the country having one of the highest Gini coefficients in the world. In such a context it is highly unlikely that a definition of the middle class that is based on an income threshold will adequately capture the political and social meanings of being middle class. The concept of the middle class originated in developed countries and is tied to the structure of these societies. Consequently, the application of the concept is often complicated in developing countries. Visagie and Posel (2013) showed that when applying the concept to the South African context a tension emerges between the inherent centrist notion embedded in the "middle class"' and the theoretical tradition because those at the centre of the income distribution are often not in skilled occupations, have little or no tertiary education and face severely constrained life chances.

To showcase an alternative capability-based definition of the middle class and to test whether it provides more sensible answers in unequal developing country settings than existing definitions, we apply it to two large scale South African data sets, dating from before and after the country's political transition. The application to South Africa is apt because the emerging middle class is pivotal in understanding South Africa's political transition and its journey to a more integrated, dynamic and pluralistic society.

We consider the enduring legacy of apartheid and the subsequent political transition by examining changes in the size and structure of the middle class in the 15 years following the political transition. However, we also consider what these observed changes mean for the future via the analytical literature that interprets these shifts as a measure of the country's economic and political prospects (Hertova et al 2010; Curry-Stevens, 2008; Rivero, et al. 2003).

We propose that the most congruent approach is to operationalize the capability perspective using a capability threshold, distinguishing those below and those above some threshold in terms of such capabilities and functionings. The underlying assumption is that the most important divide is between those who are empowered and those who are not and who consequently often rely on external support - whether from family or friends or, frequently, from the state.

In this context, the distinction between the middle class and the elite is of far less consequence. Distinguishing a upper class group above the middle class does not shed much light on the social and political behavior and contributing towards the perceived benefits for social stability that are associated with being middle class. Further support for this approach is more pragmatic: in many developing countries, including South Africa there is the further complication that most definitions 
of the elite would refer to a social layer that is so thin and poorly surveyed that it is difficult to analyse reliably with the available household data. In developing countries the "top" group is by definition a very small sliver of below $5 \%$, and for the research questions under consideration here the distinction between this group and the middle class is not important. Therefore, contrary to the traditional model of a bottom, a middle and a top, we propose a simpler, dual structure - one that focuses on the distinction between the disempowered and the empowered, with the latter then comprising the middle class.

This approach offers a more substantive and appropriate definition of the middle class in a developing country context than the traditional centrist and income-based definition of the middle class, borrowed from developed countries. The approach is preferable because it has better conceptual and analytical links to the benefits associated with the middle class, but also because a multi-dimensional measure such as Sen's capabilities approach has a more inclusive information base.

\section{Conceptual framework}

Empowerment can be described as the increased control over the decisions that affect one's life (Narayan, 2002). Capabilities act as the cornerstone of agency and the expansion of capabilities enhances and promotes agency (Narayan, 2002; Alkire and Ibrahim, 2007). Capabilities represent the opportunity available to realise certain states or achieve certain ends. It captures the freedom available to an individual to achieve well-being (Sen, 1992) and represents "effective opportunities to undertake actions and activities that they have reason to value, and be the person that they have reason to want to be." (Robeyns, 2011).

Sen defines the concept of capabilities in relation to the partner concept of functionings. Functionings refers to 'beings or doings', the different states a person can achieve in their life (Robeyns, 2005; Nussbaum, and Sen, 1993).

Capabilities reflect whether an individual has the opportunity or the freedom to achieve the functionings of their choice. Capabilities are the opportunity for realisation, while functionings are the realisations. As an example, being educated can be described as the functioning, while the opportunity to receive an education is the corresponding capability (Robeyns, 2005; Nussbaum, and Sen, 1993).

The idea of freedom to pursue your own goals and shape your own destiny is central here and is viewed as the primary moral requirement. The universal moral is for an individual to possess the capabilities required to achieve the life valued by that individual. The freedom to achieve wellbeing is determined by an individual's "real opportunities to do and be what they have reason to value" (Nayak, 2000).

Sen's capanility approach acts as a framework or paradigm through which concepts of well-being can be understood, but also in a more operational sense, to develop mechanisms for measurement and evaluation. The capabilities approach differs from conventional measures of well-being such as 
life satisfaction or income, in that the focus is on abilities and opportunities rather than ends or outcomes.

In mapping the capabilities approach to the literature on class, it important to consider the concept of conversion factors. Sen (1992) acknowledges that there may be large variation across individuals in how capabilities are translated into functionings and therefore introduces the concept of conversion factors to account for such differences. Conversion factors may operate on individual, social or environmental level. Individual conversion factors will include attitudes, abilities and expectations, social conversion factors would include public policies, social norms, discriminatory practices and hierarchies, while environmental conversion factors would refer to geography and the physical environment surrounding the individual. Jointly, capabilities and conversion factors encompass much as the concept of "life chances" associated with the work of Max Weber and broadly defined as the opportunities for improving your life. It also relates to the psychological concept of locus of control - akin to the concept of agency in economic theory - that categorises individuals based on whether life events are interpreted assuming an internal or external locus of control, i.e. whether the individual see themselves as being largely in control of their own lives or not.

In translating the capabilities approach to a framework that can be approximated with the data available and resonates with the core ideas in the literature on class, we face a number of difficult decisions. Sen and Nussbaum argue for a focus on capabilities rather than functionings, when using the capabilities approach to create a measure of welfare. The preference for capabilities is largely because it does not impose any value judgements on what constitutes a 'good life'. This also enhances comparability.

However, capabilities are rarely captured adequately - both in depth and range - in standard household surveys, while functionings are easier to measure and thus more accessible (Robeyns 2006; Sen 1992:52-3; Nayak, 2000). Additionally, it is valuable that functionings implicitly include the influence of conversion factors, because such social and individual constraints are central to class analysis. In an attempt to balance these considerations we approximate capabilities via functionings, but remaining cognisant of selecting functionings that are broad and generic to avoid applying restrictive judgements on what ends should be valued and pursued by individuals.

We proceed by following the guidelines of Robeyns (2003) to formulate an a priori list of four capabilities that distinguish the empowered middle class from the lower socio-economic groups and are theoretically linked to the economic and political benefits associated with a rising middle class. These four capabilities are: freedom from concern about survival and meeting basic needs; financial discretion and buying power; labour market power; access to information and the ability to process information.

Freedom from concern about survival and meeting basic needs manifests in terms of greater discretion about both time and expenditure. An increasing diversion of focus away from the immediate and the short term is expected to affect behaviour and decision making by extending the individual's time horizon. This is vital in terms of financial behaviour such as saving and 
investments, but also investments in human capital. Inglehart and Welzel (2009) argue that in the presence of this type of freedom, individuals have the ability to pursue higher level functionings associated with the development of self-expressive values and effective democracy.

Financial discretion and buying power empower individuals through disposable income which increases their choice set. Higher disposable income can boost entrepreneurship, consumption, savings and investment in human and physical capital (Easterly 2001).

Labour market access measures linkages to opportunities in the labour market. Wider and more equitable access to labour market opportunities is expected to enhance allocative efficiency. Additionally, because the labour market is such a crucial institution this is also an important measure of financial and social inclusion in South Africa's dualistic economy. As a measure of inclusion and integration it is expected to enhance social outcomes.

Access to information and the ability to process information influence individuals' choice set and their ability to make informed decisions. An educated and informed public encourages public accountability, which reduces the likelihood of rent-seeking and corruption and promotes good governance and effective management of public resources (Birdsall, 2010). According to Ingehart and Welzel (2009) education and access to information also increase voice and political shrewdness, which is vital for an effective democracy.

\section{Data}

The data sets used to conduct the investigation span almost 20 years and therefore enable us to look at the changes in class across a period. The Project for Statistics on Living Standards and Development (PSLSD) was conducted by the South African Labour Development Research Unit (SALDRU) in 1993. The National Income Dynamic Survey (NIDS) was also conducted by SALDRU. It is available for 2008, 2010 and 2012 and was constructed using the PSLSD survey as a framework, facilitating comparison of the two surveys.

PSLSD had 43985 respondents of which 25235 were adults and 18750 children. The NIDS surveys had 33170 respondents in 2008, of which 19763 were adults and 11407 were children. Both surveys were constructed to be nationally representative. While the NIDS survey was deliberately aligned to the format of PSLSD, there are important differences between the two surveys, and care must be taken in the comparison.

\section{Empirical estimation}

As mentioned, in searching for empirical proxies for these four capabilities, we often had to resort to using associated functionings and endowments because these are more observable than the underlying capabilities. Based on the variables available in NIDS and PSLSD, we choose ownership 
of a stove and a fridge to capture buying power and access to electricity ${ }^{2}$, adequate sanitation ${ }^{3}$ and clean water to represent the fulfilment of basic needs, the presence of an employed person in the household to represent labour market power ${ }^{4}$, literacy to capture the ability to process information and TV and radio ownership to represent access to information. Following the work of Gustafsson et al. (2010) on years of education in South Africa, respondents with education of 7 years or more were considered literate.

Assuming that capabilities are complementary, we treat each of these dimensions as a necessary condition for individual agency. Consequently, we combine the four dimensions under the assumption that failing to meet any one of the set criteria disqualifies an individual from being classified as middle class. Only when an individual meets all these criteria can the person be categorised as empowered (or middle class). Unlike many multidimensional poverty indices, we do not add up attainment scores across dimensions in conjunction with a threshold value. We argue that each of these dimensions is required for empowerment - conversely, that the absence of attainment in any of these dimensions would significantly constrain or disempower an individual, and thus disqualify him or her from being considered middle class.

Employing this definition, we end up with a 'middle class' or 'empowered group' that is much broader than income-based measures of the middle class - but also, we would argue, is a more appropriate and meaningful barometer of social and political change in our country.

While we cannot simply assume that this is a cohesive group, the use of several dimensions instead of one means that we capture a number of overlapping layers in our definition, which may plausibly enhance cohesiveness.

We choose this approach because we think this is the best approximation of the relationships between various capabilities, but it does have the added benefit of circumventing the debate about how to apportion weights when summing across dimensions.

Considering the unit of analysis, there is an inherent tension between the capabilities approach that is individual and the theory of class, which looks at households. A household level analysis would be complicated in the context of South Africa's multi-generation households because compared to developed countries, aggregation would be across a larger number of household members and span a greater range of age cohorts. There are also concerns that a household view on class may mask a significant share of the change observed over this period where many previously disenfranchised and marginalised South Africans were presented with opportunities for social advancement. Recognising that empowerment has both individual and social dimensions, our capability indicators

\footnotetext{
2 Access to electricity was defined by considering whether electricity was used for lighting. We find that even if electricity is available, households often prefer to use alternative energy sources for cooking and heating because they are cheaper or the complementary goods required to use electricity for these purposes (e.g. electric stove, or electric heaters) may for many households be too expensive to purchase.

${ }^{3}$ Adequate sanitation excluded only the no sanitation category and the bucket system

${ }^{4}$ We did not penalise households that consisted entirely of students and/or pensioners
} 
include both individual level and household level variables. The estimates are on individual level and only available for adults (individuals 18 years or older).

To compare our approach to an income based approach we choose the per capita income threshold so that the initial proportion of individuals in the middle class in 1993 would be exactly the same as the estimated middle class share using the capabilities approach. We can then compare growth in the size of the middle class between 1993 and 2008 across approaches using the same initial size. The 1993 threshold is adjusted for inflation to estimate the income-based middle class in 2008.

We also consider two potential combinations of these definitions, estimating the intersection of the two approaches (where individuals are only categorised as middle class when both the approaches define them as middle class) and the union of the two approaches (where individuals are categorised as middle class when either of the two approaches classify them as middle class).

\section{Social change and the middle class in post-apartheid South Africa}

Concerns over inequality and poverty are at the forefront of the South African policy debate. With the transition into democracy in 1994, a burgeoning middle class was expected to aid in economic development and social reformation. The rise in middle class was to reflect the development of agency and empowerment in the lower rungs of the South African class structure. It was seen as a catalyst for meaningful participation in the economy. However, two decades after the institution of democracy, efforts to redress the legacy of apartheid continue to be fraught with difficulties and evaluations regarding progress are varying. The operationisation of Sen's capabilities approach acts as a new tool with which we can investigate this progress.

Our results show that there was strong growth in the middle class between 1993 and 2008. Due to significant expansion of government services over the period and the relatively lacklustre labour market performance, we find a discrepancy between the middle class growth trajectories shown for the multi-dimensional capabilities approach compare to the traditional income approach. Table 1 shows that based on the capability definition the share of adults belonging to the middle class has grown from $27 \%$ to $48 \%$ vs. the increase from $27 \%$ to $41 \%$ for the income approach. While the slope differs, it is important to note that all approaches and also the two combined options show an increase in the middle class over this period. 
TABLE 1: Share of the middle class in South Africa, 1993, 2008, 2010 \& 2012

\begin{tabular}{|l|r|r|r|r|}
\hline & $\mathbf{1 9 9 3}$ & $\mathbf{2 0 0 8}$ & \multicolumn{1}{c|}{$\mathbf{2 0 1 0}$} & \multicolumn{1}{c|}{$\mathbf{2 0 1 2}$} \\
\hline Capabilities & 26.8 & 34.5 & 40.5 & 47.9 \\
\hline Income & 26.7 & 30.4 & 36.3 & 41.0 \\
\hline Union of capabilities and income & 38.4 & 44.9 & 53.0 & 59.7 \\
\hline $\begin{array}{l}\text { Intersection of capabilities and } \\
\text { income }\end{array}$ & 17.4 & 19.4 & 23.7 & 29.3 \\
\hline
\end{tabular}

Note: To ensure comparability the income-cut off for the middle class in 1993 was selected to achieve a group of a similar size than that estimated by the capability approach

We also consider the alignment between the capability indicator approach to defining the middle class and the traditional income definition. As mentioned above, in an attempt to make the income definition comparable to our capability approach we choose an income cut-off that would classify the same weighted proportion of individuals as middle class as we find with our capability approach in 1993 (27\%) (see Table 1). There is a lower than expected overlap between the multidimensional capability indicator measure of the middle class and a comparable income-based middle class definition. Just over $60 \%$ of the individuals who are classified as middle class based on the capability definition are also defined as middle class when using the income definition. Similarly just over $60 \%$ of adults categorised as middle class based on their income in 2008 are also viewed as middle class when applying the capability approach. Adults who are members of the middle class based on the capability definition but not according to the income definition are spread over the entire income distribution, with $41 \%$ in quintile 3 and $29 \%$ in quintile 2 . Similarly, amongst those who are members of the middle class based on their household income in 2008 but do not qualify according to the capability approach, 30\% live in households without any employed members, $30 \%$ of them do not have 7 years of education, $27 \%$ do not own stoves and more than $50 \%$ do not own fridges. The analysis shows a large discrepancy between these two approaches to classifying the middle class and consequently it is important to be cognisant of the definition employed and its assumptions and limitations.

Table 2 provides more detail regarding changes in the underlying capability dimensions. There has been notable growth in most of these indicators, confirming previous reports of significant social and economic development over this period.

The most notable of these increases is the dramatic rise in the access to electricity from $48 \%$ in 1993 to $90.1 \%$ in 2012. Associated with the expansion of electricity, we also see a steep increase in the ownership of electric goods such as fridges from $43 \%$ to $77 \%$ and in stoves from $47 \%$ to $85 \%$.

The increase in media access is modest, growing from $89 \%$ to $91 \%$. There is some crowding out of traditional mediums in favour of new technology, but this is not substantial. Access to media increases to $88 \%$ and $92 \%$ in 2008 and 2012 respectively if we broaden the definition to include mp3 players, hi-fi's, stereos, satellites and computers on the presumption that radio and TV ownership may have been crowded out by newer technology. 
TABLE 2: Comparison of dimensions, 1993, 2008 \& 2012

\begin{tabular}{|l|c|c|c|}
\hline & $\mathbf{1 9 9 3}$ & $\mathbf{2 0 0 8}$ & $\mathbf{2 0 1 2}$ \\
\hline Clean water & $85.9 \%$ & $93.5 \%$ & $95.4 \%$ \\
\hline Adequate sanitation & $83.3 \%$ & $91.1 \%$ & $94.7 \%$ \\
\hline Electricity & $47.6 \%$ & $82.5 \%$ & $90.1 \%$ \\
\hline Access to information & $88.9 \%$ & $87.6 \%$ & $91.2 \%$ \\
\hline Labour market access & $73.0 \%$ & $69.9 \%$ & $75.0 \%$ \\
\hline Basic literacy & $63.8 \%$ & $77.3 \%$ & $82.2 \%$ \\
\hline Stove & $46.8 \%$ & $70.4 \%$ & $84.7 \%$ \\
\hline Fridge & $42.9 \%$ & $61.5 \%$ & $76.6 \%$ \\
\hline
\end{tabular}

The expansion of educational attainment shows up as a rise in basic literacy levels from $64 \%$ to $82 \%$. However, the labour market access variable has hardly increased, from $73 \%$ to $75 \%$. As mentioned above, this modest increase in the employment measure vs. strong growth in government service delivery and associated indicators may help to explain the observed difference in the pace of growth of the income-based middle class and the capability-based middle class.

FIGURE 1: Waterfall chart showing contribution of each indicator in identifying the middle class, 2008

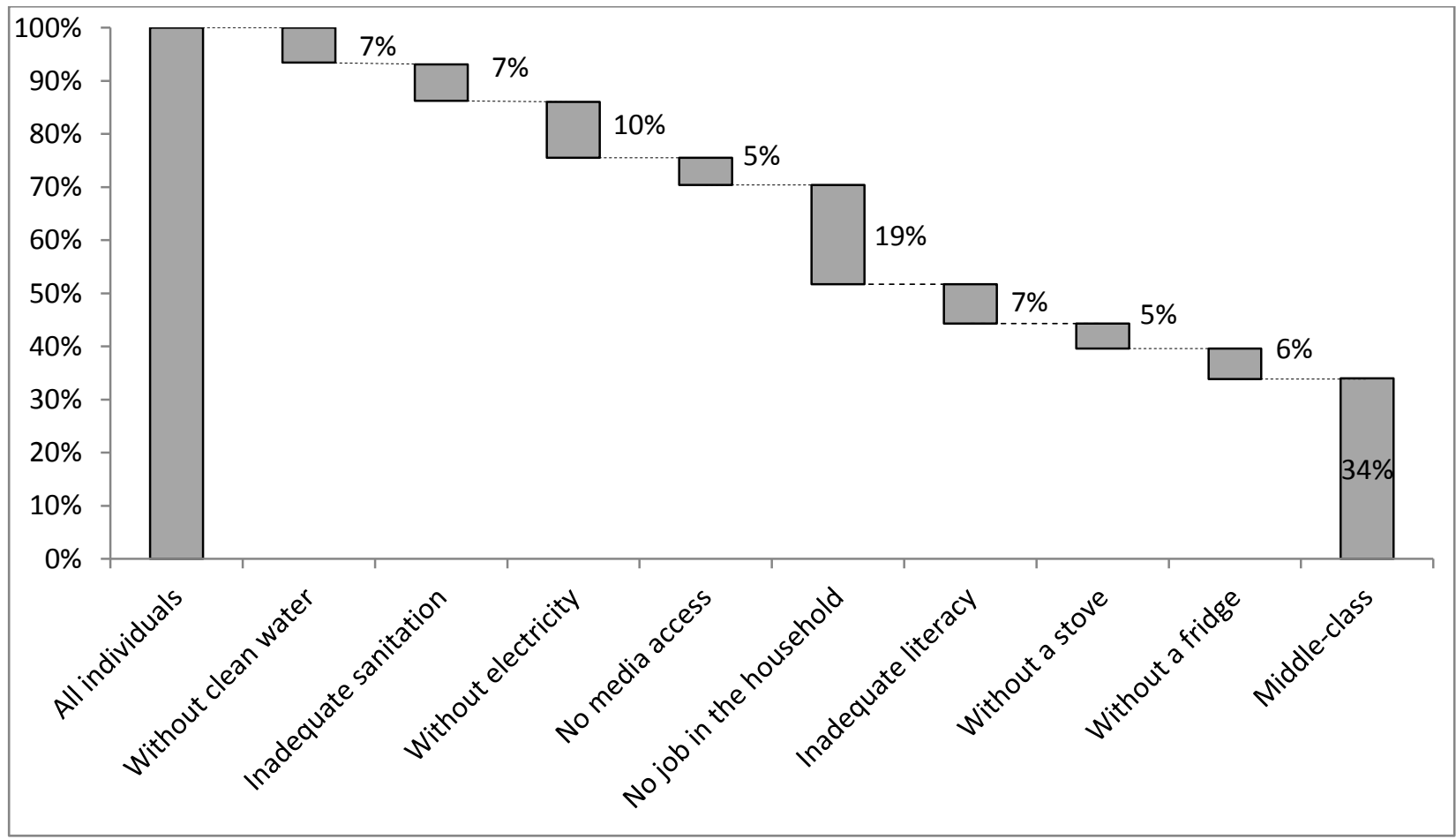

To address concerns that one indicator may be doing most of the work in identifying the middle class, we construct a waterfall chart looking at the share of individuals eliminated through each of the indicators. We first looked at basic services and ordered the remaining indicators according to their prevalence in NIDS 2008, but we reversed the order of stove and fridge because there were no 
individuals without fridges who had access to all other indicators (clean water, sanitation, electricity, media, employment, literacy and stoves).

It is evident from the graph that there is a fair degree of overlap and consensus amongst the indicators. The largest losses occur through the employment access and literacy criteria, but even these jumps are within reasonable bounds and not dominant.

As a rapid sanity check, we use the 2008 NIDS to consider whether those classified as middle class (according to the attributes and characteristics of the middle class) conform to the concept of middle class ito characteristics, life chances and financial decisions. In line with the literature around life chances. Table 3 shows that the individuals belonging to the middle class are significantly more likely to be happier, but also more hopeful and less fearful. They are also less likely to report hunger. We also consider links to the formal credit market and financial markets and find that individuals belonging to the middle class are significantly and markedly more likely to have access to a loan and insurance. Additionally, the middle class are significantly more likely to own a car and a brick house. An income-based approach to the middle class fares no better and yields estimates that are surprisingly close to that of the capability indicator approach, but interestingly, the intersection of the two definitions results in a group that conforms more closely to the concept, as measured using the prevalence of the middle class attitudes, products and assets outlined above.

TABLE 3: Attitudes, financial products and asset ownership of the middle class, 2008

\begin{tabular}{|l|c|c|c|}
\hline & $\begin{array}{c}\text { Capability } \\
\text { approach }\end{array}$ & $\begin{array}{c}\text { Income } \\
\text { approach }\end{array}$ & Intersection \\
\hline Frequently feel hopeful & 55.1 & 58.0 & 59.1 \\
\hline Happiness/life satisfaction (1 to 10) & 6.3 & 6.3 & 6.8 \\
\hline Ever went to bed hungry because of lack of food & 0.9 & 1.4 & 0.2 \\
\hline Access to loans & 38.2 & 40.7 & 53.4 \\
\hline Owns brick house & 92.7 & 88.9 & 97.0 \\
\hline Owns car & 50.9 & 50.0 & 66.3 \\
\hline
\end{tabular}

Notes: In all cases the prevalence of these attributes was significantly different from that for the remainder of the sample (those not classified as middle class)

Below we extend this analysis to different subgroups and find that since the end of apartheid there has been an expansion of the middle class in subgroups that have historically been underrepresented in the mainstream and formal economy. This provides evidence that postapartheid social and economic processes have become more inclusive and now extend more opportunities to previously marginalised and disenfranchised segments of the population.

According to Table 3 both the capability and income approaches show growth in the share of rural inhabitants belonging to the middle class. This is an important segment of the population to consider because apartheid policies restricted movement outside of the rural "homelands" for a large share of the black population. Formally, the government espoused parallel development, but South Africa's urban areas were prioritised and there was much lower spending per capita in these 
so-called "homelands". Towards the last few years of apartheid spending had already started to equalise, but there were further efforts to improve geographic equity after 1994.

Our analysis shows that the growth in the middle class has been rapid and the evidence of social change in these areas is encouraging. However, there is no consensus on the magnitude of the jump. Based on the capabilities approach the share of rural inhabitants who are middle class rose from $6 \%$ to $29 \%$ and while the income approach estimates rose from $10 \%$ to $22 \%$. Table 4 also indicates that the rural share of the middle class grew according to both the capabilities and the income approach. Notable however, is that the likelihood of being middle class remains much lower for rural inhabitants than for the average South African (cf. Table 1).

TABLE 4: Middle class membership in rural areas in South Africa, 1993, 2008, 2010 \& 2012

\begin{tabular}{|l|r|r|r|r|}
\hline & \multicolumn{1}{|c|}{$\mathbf{1 9 9 3}$} & \multicolumn{1}{|c|}{$\mathbf{2 0 0 8}$} & \multicolumn{1}{|c|}{$\mathbf{2 0 1 0}$} & \multicolumn{1}{c|}{$\mathbf{2 0 1 2}$} \\
\hline Capabilities & 5.9 & 15.1 & 19.7 & 28.6 \\
\hline Income & 10.1 & 10.9 & 16.4 & 21.8 \\
\hline Union of capabilities and income & 13.5 & 21.9 & 28.9 & 38.0 \\
\hline Intersection of capabilities and income & 3.4 & 4.5 & 7.4 & 12.5 \\
\hline Rural share of the population & 49.4 & 35.3 & 37.0 & 37.0 \\
\hline Rural share of middle class: capabilities & 10.9 & 17.7 & 18.3 & 22.1 \\
\hline Rural share of middle class: income & 18.0 & 14.2 & 16.9 & 19.7 \\
\hline
\end{tabular}

Table 5 shows that following the dismantling of discriminatory apartheid era legislation, the introduction affirmative action and black economic empowerment and a large scale transformation of public employment, there has been a surge in the share of black ${ }^{5}$ South Africans who are middle class, but also in the black share of the middle class. The trend is found across all approaches, but it is somewhat less pronounced using the income approach. The share of the black population that is classified as middle class according to the capability approach has increased from $12 \%$ to $40 \%$, while the increase in the share of black South Africans belonging to the middle class is somewhat lower for the income approach, from $12 \%$ to 32\%. Similarly, we see that the black share of the middle class has risen dramatically. Using the capability approach the proportions have risen from $32 \%$ to $64 \%$. The income approach also show increases, but of a somewhat smaller magnitude.

For the coloured population, middle class membership has increased only modestly from 53\% to $59 \%$ according to the capability approach and from $35 \%$ to $43 \%$ according to the income approach. Due to more rapid growth of the black middle class, the coloured share of the middle class shrunk over this period, but despite this shift it is important to note that the likelihood of being middle class remains higher than the population average for coloured South Africans and lower than the population average for black South Africans.

\footnotetext{
${ }^{5}$ In line with the definitions used in the two surveys and conventional categorisation in South Africa, the category 'black' includes African individuals and the category 'coloured' refers to mixed race individuals.
} 
TABLE 5: Middle class membership and race in South Africa, 1993, 2008 \& 2012

\begin{tabular}{|l|r|r|r|r|r|r|}
\hline & \multicolumn{3}{|c|}{ Black } & \multicolumn{3}{c|}{ Coloured } \\
\hline & $\mathbf{1 9 9 3}$ & \multicolumn{1}{|c|}{$\mathbf{2 0 0 8}$} & \multicolumn{2}{|c|}{$\mathbf{2 0 1 2}$} & \multicolumn{1}{c|}{$\mathbf{1 9 9 3}$} & \multicolumn{2}{c|}{$\mathbf{2 0 0 8}$} & $\mathbf{2 0 1 2}$ \\
\hline Capabilities & 11.5 & 25.5 & 39.9 & 52.9 & 46.3 & 58.9 \\
\hline Income & 12.1 & 25.5 & 32.0 & 34.5 & 45.9 & 42.6 \\
\hline Union of capabilities and income & 20.0 & 38.4 & 52.3 & 60.8 & 61.3 & 67.3 \\
\hline $\begin{array}{l}\text { Intersection of capabilities and } \\
\text { income }\end{array}$ & 4.0 & 12.8 & 19.6 & 29.1 & 30.9 & 34.3 \\
\hline Racial share in the population & 74.9 & 76.1 & 77.3 & 8.3 & 9.3 & 9.3 \\
\hline Middle class share: capabilities & 31.7 & 56.8 & 64.3 & 16.5 & 12.2 & 11.4 \\
\hline Middle class share: income & 35.3 & 53.0 & 60.3 & 10.5 & 11.6 & 9.7 \\
\hline
\end{tabular}

Similarly, Table 6 also shows that there appears to be an improvement in gender equity. We find a significant expansion in the proportion of adults living in female-headed households who are categorised as middle class according to the capabilities approach, increasing from $16 \%$ to $45 \%$ over this period. The 2012 estimate of $45 \%$ is very close to the population average of $48 \%$. Middle class membership measured according to the income approach has also expanded amongst this subgroup from $12 \%$ to $33 \%$. In the case of the income approach, the likelihood of being middle class is much lower amongst this subgroup than for the full population of South Africans, where middle class membership was 27\% in 1993 and 41\% in 2012.

TABLE 6: Middle class membership amongst female-headed households in South Africa, $1993,2008,2010 \& 2012$

\begin{tabular}{|l|r|r|r|r|}
\hline & \multicolumn{1}{|c|}{$\mathbf{1 9 9 3}$} & $\mathbf{2 0 0 8}$ & \multicolumn{1}{c|}{$\mathbf{2 0 1 0}$} & $\mathbf{2 0 1 2}$ \\
\hline Capabilities & 16.2 & 28.1 & 34.7 & 44.6 \\
\hline Income & 11.9 & 24.0 & 24.2 & 33.1 \\
\hline Union of capabilities and income & 21.5 & 36.7 & 43.0 & 53.3 \\
\hline Intersection of capabilities and income & 7.2 & 15.4 & 15.8 & 24.5 \\
\hline Female-headed houshold share of population & 25.9 & 38.8 & 49.8 & 58.8 \\
\hline $\begin{array}{l}\text { Female-headed households' share of middle class: } \\
\text { capabilities }\end{array}$ & 16.1 & 32.0 & 42.8 & 54.7 \\
\hline $\begin{array}{l}\text { Female-headed households'share of middle class: } \\
\text { income }\end{array}$ & 11.2 & 25.4 & 33.1 & 47.5 \\
\hline
\end{tabular}

\section{Looking ahead: Capabilities and aspirations}

There has also been much discourse on the relation between capabilities, aspirations and social mobility. To investigate how the concept of capabilities relates to the social mobility, we consider aspirations by comparing the rung of the ladder where individuals place their households now and where they expect to see their household two years and five years later. Aspirations tend to be high 
with $85 \%^{6}$ of respondents interviewed in 2008 expecting to stand on a higher rung of the socioeconomic ladder in five years' time. On average individual respondents expected to climb a rung higher on the socio-economic ladder over the next two years and rise two rungs over the next five years.

\section{FIGURE 2: Local polynomial of aspired and actual social mobility by years of education, 2008 - 2012}

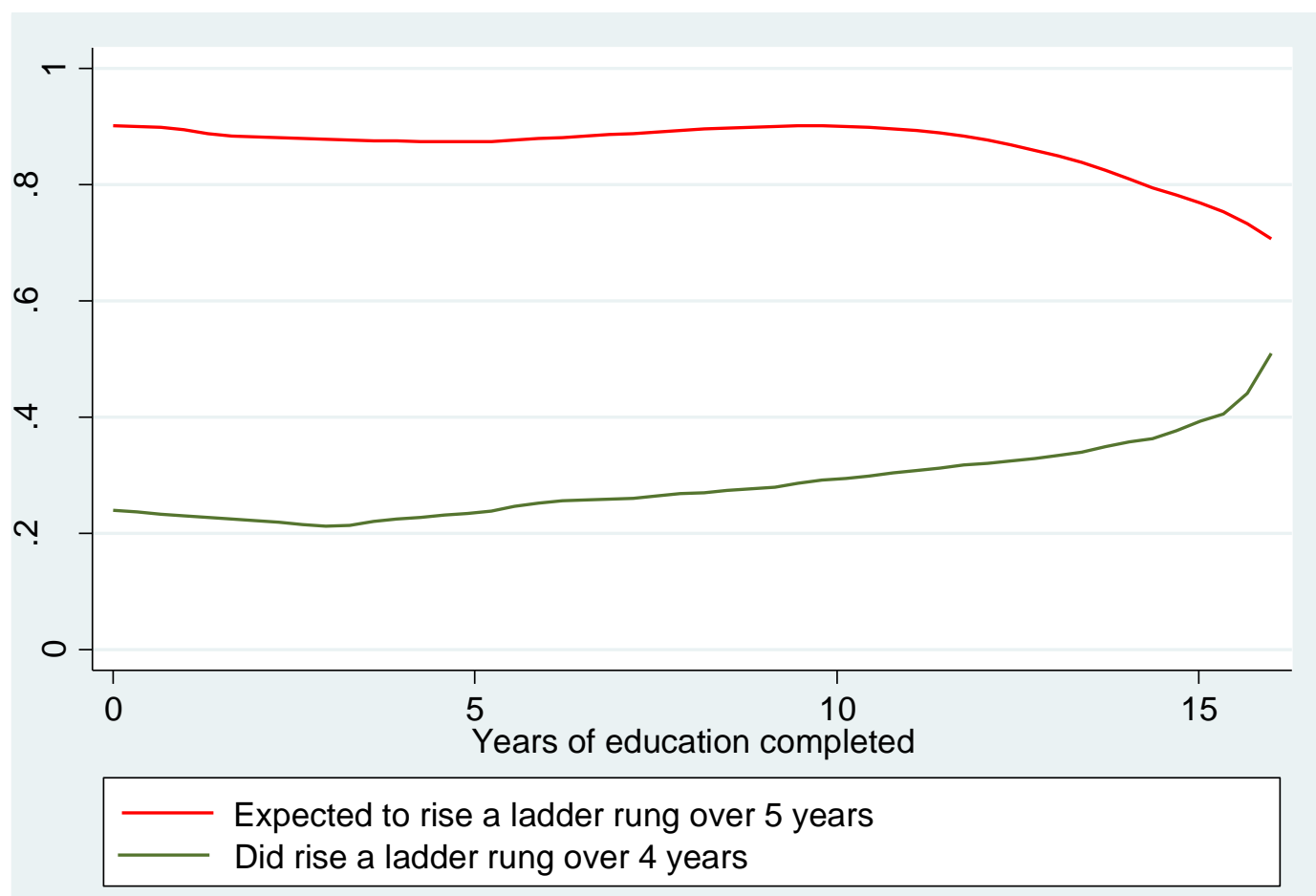

kernel $=$ epanechnikov, degree $=3$, bandwidth $=3.18$

We also investigate partial correlations between social aspirations, per capita income and a set of individual characteristics and geographical variables including race, age, gender, rural location and province. We find that aspirations about social mobility are higher amongst black South Africans and younger and poorer individuals. We check whether it may be partly driven by high selfassessed initial positions. If individuals assess themselves to already be at the top end of the ladder, this limits their ability to express ambitions for further social mobility on this six-rung ladder scale. However, if we eliminate those at the top of the distribution, the changes in the coefficient patterns are barely noticeable.

Contrary to expectations, we find that dummies indicating membership of the middle class are negative and significant (jointly in the case where we include both measures), indicating that the middle class tend to have lower expectations and aspirations than others. This remains true if we

\footnotetext{
${ }^{6}$ These estimates were lower in 2010 and 2012, but remained very high with a respective $73 \%$ and $80 \%$ of respondents expecting to climb at least one rung of the ladder over the next 5 years.
} 
re-run the regressions, but eliminate respondents who are already standing on the top rung of the ladder.

This stands in contrast findings elsewhere that the poor usually suffers from too low aspirations and the lack of "capacity to aspire" (Appadurai, 2004). This strengthens an interpretation that high aspirations and heightened aspirations amongst poor blacks may be largely attributable to expectations of enhanced social mobility and better lives relating to South Africa's political transition.

We examine this further and find that more education decreases the gap between actual and anticipated social mobility. Individuals with more years of education tend to have lower expectations about climbing the socio-economic ladder, but at the same time their households are more likely to climb one rung (one sixth) of the income ladder between 2008 and 2012. The sample is limited to individuals between 28 and 50 and excludes those on the top rung (perceived top rung for expectations and actual top one sixth for per capita income).

It is concerning that in the South African case there appears to be high expectations around social mobility and these expectations are not related to individual prospects for social mobility. The relationship between education and aspirations reflects an undervaluation of the contribution of education to labour market prospects and social mobility by the less educated households, pointing to an alternative route for poverty traps. There is little evidence of low aspirations amongst the poor and thus it appears that for most vulnerable and poor South Africans the first challenge relating to empowerment would not be to raise aspirations and "unlock agency" as Conradie and Robeyns, 2013 have argued, but rather to manage expectations around social mobility and direct energy invested in pursuing aspirations by providing guidance and assistance in navigating the system. Without a reliable compass and map, the desire, willingness and ability to travel may not mean much.

\section{Conclusion}

In a polarised and highly unequal country such as South Africa, it is unlikely that a definition of the middle class that is based on an income threshold will adequately capture the political and social meanings of being middle class. We propose a multi-dimensional definition, rooted in the ideas of empowerment and capability, and find that the 'empowered middle class' has expanded significantly since 1993. It also is much larger than when measured in terms of income.

If one wants to transfer the concept of a middle class in a meaningful way to the milieu of a developing country, i.e. whilst retaining the most central meaning and usefulness of the term, then essentially one has to capture the level or degree of individual empowerment that exists - and not just how much (disposable) income people earn. The concept of empowerment is aligned with human development and the characteristics associated with self-sufficiency and each person's capacity to be in control of his or her own life. Such an approach better captures the pathways for the social and political benefits associated with the 'middle class' as conventionally understood. For example, people with better education or better access to reliable information are thought to be 
more able to navigate their own destinies and be less vulnerable to shocks like economic ups-anddowns and workplace, personal, domestic or national calamities.

We also consider where those whom we categorise as the middle class view their position in society and find that they consistently underestimate their rank. However, those individuals that we classify as middle class are more likely to be optimistic about their prospects for getting ahead than individuals who are comparable in terms of the self-ranked positions. Black South Africans are more likely than other South Africans to underestimate their own social rank, but are simultaneously also more ambitious in their expectations for the future. It is concerning that less educated individuals tend to have higher expectations of how fast they will ascend the socioeconomic ladder. This finding should be further explored because the freedom to make meaningful choices means very little if individuals do not have accurate information about how their choices map to social prospects.

Our research shows a strong rise in the middle class since the transition to democracy in 1993. According to our capability-based approach the middle class has increased from $27 \%$ in 1993 to $48 \%$ in 2012. Our results suggest that, in terms of this new definition, South Africa has made significant progress over the two decades. The indicators of empowerment provide evidence that, contrary to much public opinion, the post-apartheid period has produced a substantial and broad improvement in empowerment. There has been a substantial increase in the number and proportion of South Africans that can be regarded as reasonably self-sufficient and empowered and also in the proportion of black South Africans that belong to this group. Post-apartheid policies and interventions aimed at reparation appear to have had an impact. The society and the economy have become more inclusive, with rural inhabitants, blacks and female-headed households being more likely to belong to the middle class and representing a larger share of the middle class than before the political transition.

There have been significant strides in most of the individual capability indicators, including, the increase in access to electricity from $48 \%$ to $90 \%$, the associated rise in the ownership of stoves from $47 \%$ to $85 \%$ and fridge ownership from $43 \%$ to $77 \%$. There has also been sizable expansion in access to clean water and adequate sanitation. This represents significant advances in freedom from concern about survival and meeting basic needs and also signals improvements in buying power.

The ability to process information has improved with basic literacy increasing from $64 \%$ to $82 \%$. However, these improved capabilities have not been rewarded with a proportional increases in access to the labour market. It is disconcerting that links to the labour market improved only slightly - from $73 \%$ to only $75 \%$ - over this period of almost 20 years, especially since our criterion only requires that someone in the household need to be employed.

This sluggish response may be related to inadequate measurements of education because our surveys capture only the years of education, and not the quality. Studies have shown that South Africa's quality of education lags far behind that of international peers and many of their African neighbours (Van der Berg, et al, 2011). Social conversion factors could also play a role. The 
lacklustre performance of the labour market has restricted opportunities for individuals to translate empowerment and untapped capabilities into productive employment and earned income - which is likely to be an on-going constraint to development and the expansion of the middle class in South Africa. The sluggish labour market also helps to explain the lower growth in the middle class observed when using the income definition, compared to the much steeper trend we see when using the capabilities definition.

Lastly, capabilities reflect individual choice sets and in many cases informed and empowered decision making is assumed. But it may be important to consider how choices map to imagined consequences and prospects in future research. Surveys rarely capture information about selfadvancement strategies and individual expectations of social mobility, yet inaccurate or incomplete information on choices and the pay-offs to choices may prevent individuals from fulfilling their potential and pursuing their dreams. This may also reflect a shortcoming of the mainstream interpretation of the capabilities approach. Assuming that individuals are inherently resourceful and can find the best way to pursue their own goals is compelling because it avoids the traps of paternalism and patronage, but in doing so too blindly we can ignore an important constraint and source of injustice and inequity. In some instances freedom and raw potential may not mean much without a deeper understanding of conversion factors broadly, but perhaps also specifically, of how young people attempt to navigate their futures by converting their abilities and potential into the functionings they desire to live a good and meaningful life.

\section{References}

Appadurai, A. 2004. 'The capacity to aspire: culture and the terms of recognition'. In: Rao V. and M. Walton (eds.) Culture and public action. Stanford, Stanford University Press: 185- 209.

Alsop, R. and Heinsohn, N. 2005. Measuring Empowerment in Practice: Structuring Analysis and Framing Indicators. World Bank Policy Research Working Paper 3510.

Alkire, S. and Ibrahim, S. 2007. Agency and Empowerment: A proposal for internationally comparable indicators. Oxford Development Studies.

Alkire, S. Concepts and Measures of Agency. OPHI Working Paper Series.

Birdsall, N, 2010. 'The (Indispensable) Middle Class in Developing Countries'. In Kanbur, R \& Spence, M (Eds.), Equity and Growth in a Globalizing World. World Bank, Washington D.C.

Conradie, I. and Robeyns, I. 2013. Aspirations and Human Development Interventions. Journal of Human Development and Capabilities 14(4): 559-580

Curry-Stevens, A. 2008. Building the case for the study of the middle class: shifting our gaze from margins to centre. International Journal of Social Welfare 17(4): 379-389

Easterly, W. 2001. The Middle Class Consensus and Economic Development. Journal of Economic Growth 6: 317-335

Gustafsson, M., Van der Berg, S., Shepherd, D. and Burger, C. 2010. The costs of illiteracy in South Africa. Stellenbosch Economic Working Papers 14/10. Stellenbosch University

Hertova, D., L.F. Lopez-Calva and E. Ortiz-Juarez (2010). Bigger... but Stronger? The Middle Class in Chile and Mexico in the Last Decade. Research for Public Policy, Inclusive Development, ID-02-2010, RBLAC-UNDP, New York.

Hill, M. T. 2003. Development as empowerment. Feminist Economics 9(2-3): $117-135$

Inglehart, R. and Welzel, C. 2009. Development and Democracy: What We Know about Modernization Today. Foreign Affairs (March/April): 33-41 
Narayan, D. 2002. Empowerment and Poverty Reduction: A Sourcebook. Chapter 2: What is Empowerment? World Bank. PREM

Narayan, D and Petesch, P. (eds.) 2007. Moving Out of Poverty: Cross-Disciplinary Perspectives on Mobility. Volume 1. Palgrave Macmillan and The World Bank

Nayak, P. 2000. Understanding the Entitlement Approach to Famine. Journal of Assam University 1(1): 60-65.

Phadi, M. \& Ceruti, C. 2011. Multiple meanings of the middle class in Soweto, South Africa. African Sociology Review 15(1): $88-108$.

Rivero, C, Du Toit, P, \& Kotze, H, 2003. Tracking the Development of the Middle Class in Democratic South Africa. Politeia 22(3): 6-29.

Robeyns, I. 2005. The Capability Approach: a theoretical survey. Journal of Human Development. 6(1): 93-114.

Schlemmer, L. 2005. 'South Africa's new middle class'. Ch. 5 in: Ann Bernstein and Sandy Johnston (Eds.), The next decade: Perspectives on South Africa's growth and development. Centre for Development and Enterprise, Johannesburg: 112-140

Sen, A. 2003. 'Development as Capability Expansion'. In: Fukuda-Parr, S., et al. Readings in Human Development. New Delhi and New York: Oxford University Press.

Van der Berg, S., Burger, C., Burger, R., De Vos, M., Du Rand, G., Gustafsson, M., Moses, E., Shepherd, D., Spaull, N., Taylor, S., Van Broekhuizen, H., Von Fintel, D. 2011. Low quality education as a poverty trap. Stellemnpsch University. Available from: www.pan.org.za/node/8431.

Visagie, J. 2015. Growth of the middle class: Two perspectives that matter for policy. Development Southern Africa 32(1): 3-24.

Welzel, C. and Inglehart, R. 2008. The Role of Ordinary People in Democratization. Journal of Democracy 19 (1): 126-140.

Welzel, C. and Inglehart, R. 2009. Development and Democracy: What We Know about Modernization Today. Foreign Affairs. March. 